\title{
Efficacy of a Novel Annular Closure Device after Lumbar Discectomy in Korean Patients : A 24-Month Follow-Up of a Randomized Controlled Trial
}

\author{
Pyung Goo Cho, Dong Ah Shin, ${ }^{2}$ Sang Hyuk Park, ${ }^{3}$ Gyu Yeul $\mathrm{Ji}^{4}$ \\ Department of Neurosurgery, Ajou University College of Medicine, Suwon, Korea \\ Department of Neurosurgery, ${ }^{2}$ Yonsei University College of Medicine, Seoul, Korea \\ Department of Neurosurgery, ${ }^{3}$ Hwalkichan Hospital, Goyang, Korea \\ Department of Neurosurgery, ${ }_{4}^{4}$ Cham Teun Teun Research Institute, Seoul, Korea
}

Objective : Lumbar discectomy is an effective treatment for lumbar disc herniation (LDH); however, up to 2-18\% of patients with LDH have experienced recurrent disc herniation. The purpose of this study was to evaluate the efficacy of a novel annular closure device (ACD) for preventing LDH recurrence and re-operation compared with that of conventional lumbar discectomy (CLD).

Methods : In this prospective randomized controlled trial, we compared CLD with discectomy utilizing the Barricaid ${ }^{\varpi}$ (Intrinsic Therapeutics, Inc., Woburn, MA, USA) ACD. Primary radiologic outcomes included disc height, percentage of preoperative disc height maintained, and re-herniation rates. Additional clinical outcomes included visual analog scale (VAS) scores for back and leg pain, Oswestry Disability Index (ODI) scores, and 12-item short-form health survey (SF-12) quality of life scores. Outcomes were measured at preoperation and at 1 week, 1, 3, 6, 12, and 24 months postoperation.

Results : Sixty patients (30 CLD, 30 ACD) were enrolled in this study. At 24-month follow-up, the disc height in the ACD group was significantly greater than that in the CLD group (11.4 \pm 1.5 vs. $10.2 \pm 1.2 \mathrm{~mm}, p=0.006)$. Re-herniation occurred in one patient in the ACD group versus six patients in the CLD group $\left(\chi^{2}=4.04, p=0.044\right)$. Back and leg VAS scores, ODI scores, and SF-12 scores improved significantly in both groups compared with preoperative scores in the first 7 days following surgery and remained at significantly improved levels at a 24-month follow-up. However, no statistical difference was found between the two groups.

Conclusion : Lumbar discectomy with the Barricaid ${ }^{\otimes}$ (Intrinsic Therapeutics, Inc.) ACD is more effective at maintaining disc height and preventing re-herniation compared with conventional discectomy. Our results suggest that adoption of ACD in lumbar discectomy can help improve the treatment outcome.

Key Words : Intervertebral disc disease · Discectomy · Herniated disc · Barricaid.

- Received : March 15, 2019 •Revised : May 15, 2019 •Accepted : May 23, 2019

- Address for reprints : Gyu Yeul Ji

Department of Neurosurgery, Cham Teun Teun Research Institute, 547 Siheung-daero, Guro-gu, Seoul 08392, Korea

Tel : +82-70-4268-7215, Fax : +82-2-851-9403, E-mail : jivag091@gmail.com, ORCID : https://orcid.org/0000-0002-8818-5091

This is an Open Access article distributed under the terms of the Creative Commons Attribution Non-Commercial License (http://creativecommons.org/licenses/by-nc/4.0) which permits unrestricted non-commercial use, distribution, and reproduction in any medium, provided the original work is properly cited. 


\section{INTRODUCTION}

Lumbar discectomy is a common surgical procedure performed to relieve symptoms of lumbar disc herniation (LDH), particularly in patients unresponsive to conservative treatment ${ }^{5,6}$. Discectomy addresses radicular symptoms by removing the extruded disc material, thus relieving the symptoms associated with nerve root compression. However, a substantial proportion of the patient population is left with persistent symptoms following discectomy. Discectomy patients reported a postoperative dissatisfaction of $10 \%$ to $30 \%{ }^{3,4)}$ and require additional treatment.

In general, patients with larger annular defects have higher rates of re-herniation because of the compromised integrity and competence of the annulus. For defects of $>6 \mathrm{~mm}$ wide, a re-herniation rate of up to $27 \%$ has been reported, as opposed to only $4.8 \%$ for narrower defects ${ }^{3)}$. Similarly, patients with defect sizes more than $54 \mathrm{~mm}^{2}$ have reported a re-herniation rate of $18 \%$, which is significantly greater than the $4.7 \%$ noted in defects below $36 \mathrm{~mm}^{2}{ }^{13)}$. Re-operation following discectomy occurs in approximately $20 \%$ of cases ${ }^{11)}$, with re-herniation occurring at a rate of $2-18 \%{ }^{3,4,12,19)}$ and symptomatic re-herniation of $3-27 \%{ }^{4,5)}$.

A novel annular closure device (ACD) has been developed to improve the outcomes in conventional discectomy. This device has been in clinical use since 2008. It has demonstrated low rates of re-herniation, excellent maintenance of disc height ${ }^{1,9,14)}$, and an ability to decelerate facet joint degeneration $^{17)}$. Previous studies on this device included Caucasian patients. Asians have smaller vertebra and different ratio of cortices ${ }^{8)}$. Thus, in this study, we aimed to evaluate the efficacy of ACD in improving outcomes following lumbar discectomy compared with that of conventional discectomy in Korean patients.

\section{MATERIALS AND METHODS}

\section{Study design and patient selection}

All patients were selected from Cham Teun Teun Hospital and Severance Hospital of Yonsei University Medical Center. The Institutional Review Board of Cham Teun Teun Hospital approved the study (IRB approved No. GTIRB-13-005). All patients signed an approved informed consent, and the study was registered publicly prior to enrollment. In this prospective randomized controlled study, a total of 60 patients who were suffering from sciatica unresponsive to conservative treatment of at least 6 weeks duration were included. Patients who met inclusion criteria were selected and asked to consider participating in this clinical trial. Then, patients who agreed to participate in the trial were assigned to the ACD group or the conventional lumbar discectomy (CLD) group using computer-generated randomization codes with a block size of five. To ensure the concealment of intervention assignment, an opaque, sealed envelope that contained randomization codes was opened 1 day prior to the surgery by a blinded clinical research assistant. LDH was confirmed by the presence of localized radicular symptoms and radiographic confirmation via computer tomography and/or magnetic resonance imaging. Patients were randomly divided into two groups of 30 and underwent posterior lumbar discectomy, as follows. In the ACD group, a limited discectomy was followed by implantation of the ACD. In the CLD group, patients underwent CLD alone.

Patient inclusion and exclusion criteria were adopted following previously published protocols ${ }^{10,14,17}$. Patients were eligible for inclusion if they presented with persistent sciatica with radiographically confirmed herniation and were aged 18 to 75 years. No limitations were placed on the defect height, width, or area, except as defined by the manufacturer's instructions for use. Patients were excluded if they met any of the following characteristics : previous back operation, foraminal or extraforaminal disc herniation, extraspinal cause of sciatica, pre-existing spinal pathology, bone mineral density T-score less than -2.0 (for subjects requiring dual-energy X-ray absorptiometry), scoliosis greater than 10 degrees, and other abnormalities, such as spondylolysis and spondylolisthesis, that would potentially interfere with the surgical procedure.

\section{ACD}

The Barricaid ${ }^{\circledR}$ endoprosthesis (Intrinsic Therapeutics, Inc., Woburn, MA, USA) is an implantable ACD designed for use as an adjunct to lumbar discectomy. It functions by blocking the annular defect and maintaining the nucleus pulposus within the anatomic confinement of the disc space. The device consists of two components : a rigid titanium bone anchor ensuring proper fixation on the selected adjacent vertebral body, and a flexible polymer mesh that blocks the defect and prevents further migration of disc material (Fig. 1). The 
(A)

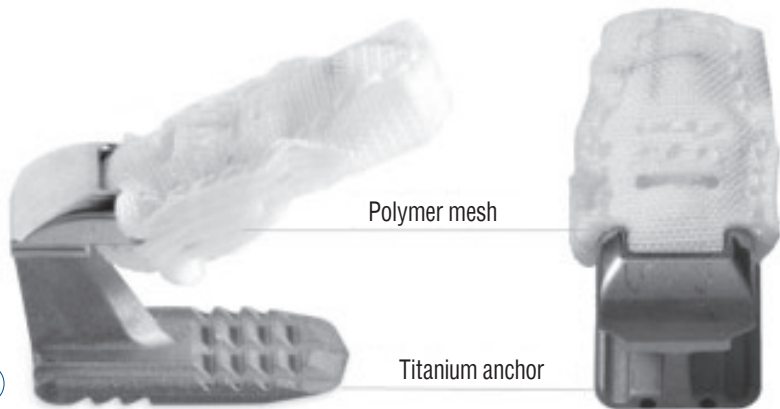

(B)

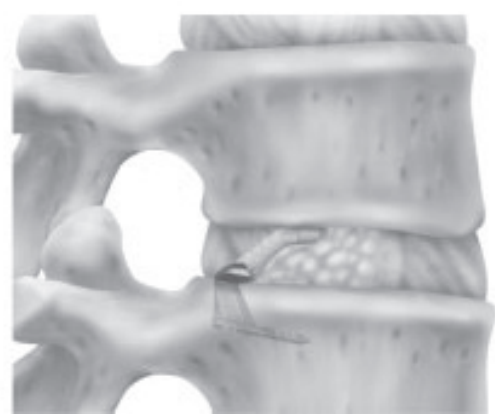

Fig. 1. The Barricaid ${ }^{\circledast}$ (Intrinsic Therapeutics, Inc., Woburn, MA, USA) implant design. This is formed from a flexible mesh comprising multiple layers of counter-angulated fibers and a strong titanium bone anchor (A). Position of implant in intervertebral space (B).

mesh contains a radiopaque platinum-iridium marker that is embedded in the anchor and allows for radiological identification during implantation. The device has different mesh widths to accommodate varying defect widths.

\section{Surgical techniques}

Discectomies were performed under a standard surgical procedure by the same senior neurosurgeon ${ }^{15}$. Prophylactic antibiotics were administered upon initiation of the surgical procedure. A medial incision was made for unilateral approach to the interlaminar space.

In patients randomized to the $\mathrm{ACD}$ group, the $\mathrm{ACD}$ was inserted under fluoroscopic control after discectomy (Fig. 2). In the CLD group, conventional discectomy was performed per standard surgical approach. Following discectomy, the volume of the removed disc material was dry measured and recorded. Procedural duration was recorded for all participants. After surgery, patients were discharged with postoperative instructions according to the surgeon's discectomy protocol. No additional bracing or other activity instructions were given to any patient.

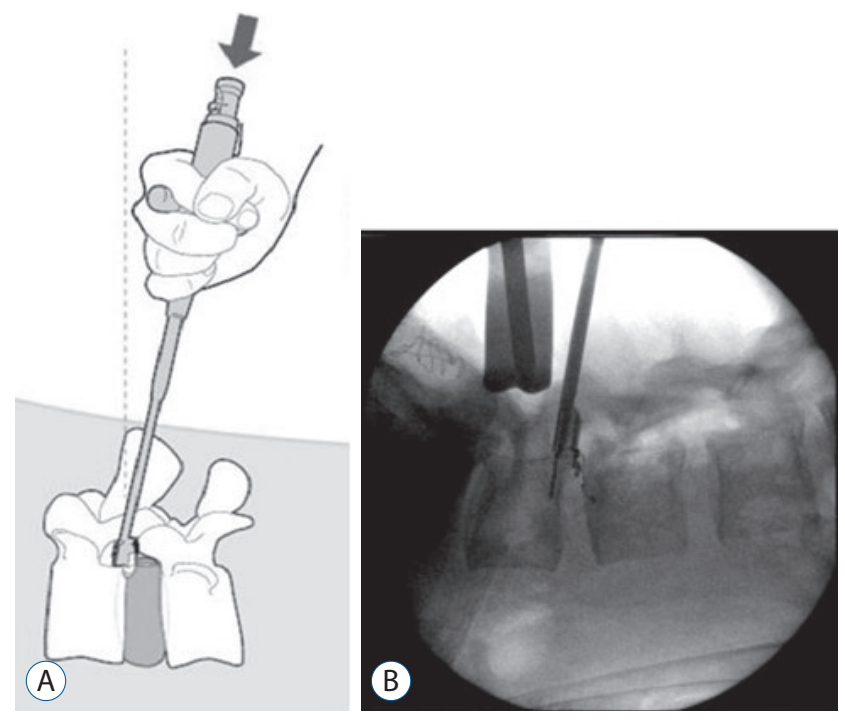

Fig. 2. Barricaid ${ }^{\oplus}$ (Intrinsic Therapeutics, Inc., Woburn, MA, USA) endoprosthesis implanted in targeted disc space. A : Schematic representation of device by means of specialized delivery tool. Arrow : fixed the Barricaid to the upper vertebral body using a specialized delivery tool. $\mathrm{B}$ : X-ray image of positioned device in L4/5 intervertebral space.

\section{Outcome assessment}

Patients were assessed postoperatively at 1 week and 1, 3, 6, 12 , and 24 months. Primary outcomes included disc height, calculated as the average of the anterior and posterior disc heights, measured on standing lateral radiographs. Postoperative disc height was expressed as both a raw value and as a percentage of the preoperative height. Additional outcomes included patient-reported pain, measured using the visual analog scale (VAS), ranging from 0 to 100 . Back and leg pain were recorded separately. Disability was assessed with the Oswestry Disability Index (ODI), which uses scores ranging from 0 to 100 to reflect the degree of disability in patients with low back pain, where higher scores represent more severe disability ${ }^{16}$. Health-related quality of life was assessed using the Medical Outcomes Study 12-item short-form health survey (SF-12) scale, which is composed of mental and physical components, where a higher score represents a better quality of life ${ }^{2}$. Complications including re-herniation were recorded at follow-up where appropriate. Re-herniation is defined as newly occurred the same side radiculopathy at least 3-point leg VAS and a herniation on the same disc space and on the same side of a previously operated disc level in magnetic resonance imaging (MRI) during follow up period. MRI was performed only in patients with suspected re-herniation to confirm a recurrence. 


\section{Statistical analysis}

For all quantitative data, descriptive statistics were calculated and recorded as mean and standard deviation. Betweengroup comparisons for numerical variables were made with the unpaired t-test assuming unequal variances and for categorical variables using the two-tailed chi-square test. Statistical significance was set a priori at $p<0.05$.

\section{RESULTS}

\section{Descriptive statistics}

Descriptive statistics are summarized in Table 1. A total of 60 patients were enrolled in the study : 30 in the ACD group and 30 in the CLD group. Nineteen patients were lost to follow-up. At 24 months, data were available for 20 patients in the ACD group and 21 in the CLD group (Fig. 3). No significant differences were noted in demographic comparisons, including age, sex ratio, body mass index, preoperative symptom

Table 1. Demographics and characteristics in ACD and CLD group

\begin{tabular}{|c|c|c|c|}
\hline & $A C D$ & CLD & $p$-value \\
\hline Number & 30 & 30 & \\
\hline Age (years) & $41.37 \pm 10.86$ & $42.63 \pm 11.51$ & 0.663 \\
\hline $\operatorname{Sex}(M: F)$ & $20: 10$ & $25: 5$ & 0.136 \\
\hline BMI & $24.41 \pm 3.40$ & $24.43 \pm 3.23$ & 0.984 \\
\hline Symptom duration (weeks) & $22.13 \pm 15.81$ & $33.30 \pm 48.59$ & 0.236 \\
\hline Operation level & & & 0.374 \\
\hline L3-L4 & 1 & 4 & \\
\hline$\llcorner 4-\llcorner 5$ & 17 & 15 (or 13*) & \\
\hline L5-S1 & 12 & 11 (or 13*) & \\
\hline Herniation classification & & & 0.078 \\
\hline Protrusion & 5 & 3 & \\
\hline Extrusion & 16 & 24 & \\
\hline Sequestration & 9 & 3 & \\
\hline Operation time (minutes) & $143.33 \pm 21.43$ & $126.17 \pm 23.37$ & 0.004 \\
\hline $\begin{array}{l}\text { Preoperative disc height } \\
(\mathrm{mm})\end{array}$ & $13.3 \pm 1.2$ & $12.9 \pm 1.7$ & 0.297 \\
\hline Volume of removed disc (mL) & $0.5 \pm 0.3$ & $0.9 \pm 0.6$ & 0.009 \\
\hline
\end{tabular}

Values are presented as mean \pm standard deviation or number (\%) unless otherwise indicated. *Have meant that the patient had lumbarization and can belong to either $L 4-L 5$ or L5/S1 level. ACD : annular closure device, CLD : conventional lumbar discectomy, $\mathrm{M}$ : male, $\mathrm{F}$ : female, BMI : body mass index duration, disc level, and herniation classification, between the two groups. No significant differences were also noted in preoperative disc height (Table 1) and preoperative clinical scores, such as VAS for back pain and leg pain, ODI scores, and short form SF-12, between both groups (Table 2).

\section{Surgical procedure}

In all 30 patients in the ACD group, the ACD was implanted at the caudal endplate. An 8-mm implant was used in $83 \%$ $(25 / 30)$ of the patients, and a $10-\mathrm{mm}$ implant in the remaining $17 \%(5 / 30)$. The mean surgical time in the ACD group was significantly longer than that in the control group (143.33土 21.43 vs. $126.17 \pm 23.37$ minutes, $p=0.004$ ) (Table 1 ). The volume of the removed disc material was significantly less in the ACD group compared with the CLD group (0.5 \pm 0.3 vs. $0.9 \pm$ $0.6 \mathrm{~mL} ; p=0.009)$.

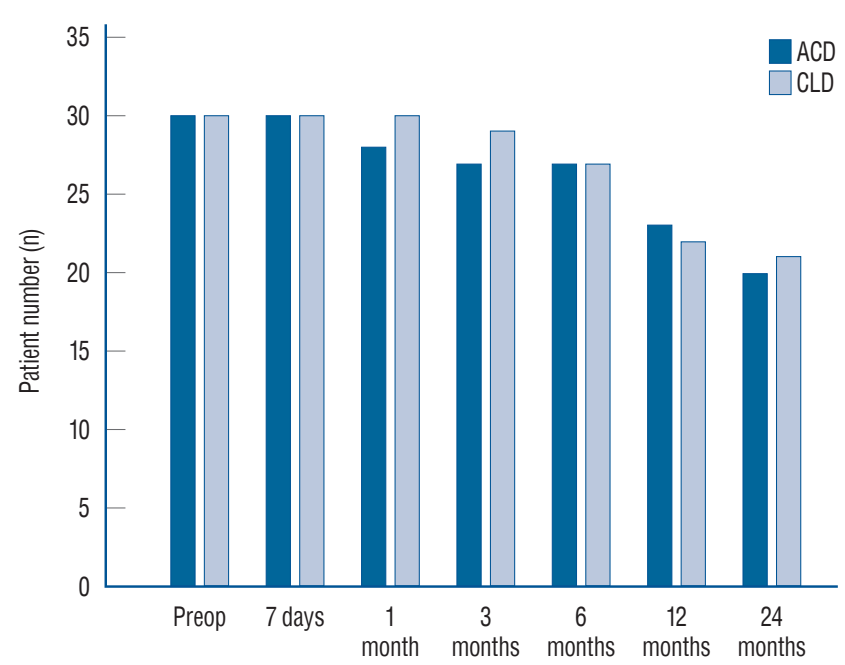

Fig. 3. Number of follow-up patients from preoperative to 24-month follow-up. ACD : annular closure device, CLD : conventional lumbar discectomy.

Table 2. Preoperative clinical outcomes of VAS, ODI, and SF-12

\begin{tabular}{lccc}
\hline Outcome & ACD & CLD & $p$-value \\
\hline VAS back pain & $58 \pm 32$ & $64 \pm 23$ & 0.408 \\
VAS leg pain & $70 \pm 31$ & $63 \pm 26$ & 0.348 \\
SF-12 P & $17 \pm 5$ & $17 \pm 6$ & 0.853 \\
SF-12 M & $23 \pm 6$ & $23 \pm 6$ & 1.000 \\
ODI & $47 \pm 15$ & $52 \pm 24$ & 0.361 \\
\hline
\end{tabular}

Values are presented as mean \pm standard deviation. VAS : visual analog scale, ODI : Oswestry Disability Index, SF-12 : 12-item short-form health survey, SF-12 P : quality of life physical, SF-12 M : quality of life mental 


\section{Disc height}

No significant difference was found in disc height between the two groups preoperatively (ACD : $13.3 \pm 1.2$ vs. CLD : $12.9 \pm$ $1.7 \mathrm{~mm}, p=0.297$ ) (Table 3). The disc height in the ACD group was maintained and was significantly greater than that in the CLD group in the first 7 days following surgery (ACD : 13.6 \pm 1.2 vs. CLD : $11.8 \pm 1.7, p=0.01)$. At 24 months, the disc height in both groups decreased significantly compared with the preoperative disc height (ACD : $11.4 \pm 1.5$ vs. $13.3 \pm 1.2 \mathrm{~mm}$, $p<0.001$; CLD : $10.2 \pm 1.2$ vs. $12.9 \pm 1.7 \mathrm{~mm}, p<0.001)$, with taller disc height in the ACD group than in the CLD group (11.4 \pm 1.5 vs. $10.2 \pm 1.2 \mathrm{~mm}, p=0.006$ ) (Table 3 ). When evaluated as a percentage of preoperative measures, the disc height was maintained to a significantly greater extent in the ACD group than in the CLD group $(86.3 \pm 11.5 \%$ vs. $79.2 \pm 10.0 \%, p=0.04$ ) (Table $4)$.

Table 3. Disc height changes from preoperative to 24 -month follow-up

\begin{tabular}{lccc}
\hline & ACD $(\mathrm{mm})$ & CLD $(\mathrm{mm})$ & $p$-value \\
\hline Preoperative & $13.3 \pm 1.2$ & $12.9 \pm 1.7$ & 0.297 \\
Postoperative & & & \\
7 days & $13.6 \pm 1.2$ & $11.8 \pm 1.7$ & 0.001 \\
1 month & $13.4 \pm 1.2$ & $12.1 \pm 1.9$ & 0.003 \\
3 months & $12.7 \pm 1.3$ & $11.2 \pm 1.6$ & 0.001 \\
6 months & $12.2 \pm 1.4$ & $10.9 \pm 1.6$ & 0.001 \\
12 months & $12.0 \pm 1.3$ & $10.8 \pm 1.2$ & 0.007 \\
24 months & $11.4 \pm 1.5^{*}$ & $10.2 \pm 1.2^{*}$ & 0.007 \\
\hline
\end{tabular}

Values are presented as mean \pm standard deviation. *Have meant that significant difference compared to preoperative disc height. ACD : annular closure device, CLD : conventional lumbar discectomy

\section{Patient-related outcomes}

At the preoperative period, no significant differences were found in VAS scores for back or leg pain, disability index, and physical and mental SF-12 scores (Table 2) between the ACD and CLD groups. Comparisons of preoperative and postoperative (24 months) clinical outcomes are listed in Table 5.

VAS back scores significantly improved at one week after surgery compared to before surgery (ACD : $62 \pm 29$ vs. $18 \pm 14$, $p<0.001$; CLD : $66 \pm 29$ vs. $26 \pm 17, p<0.001)$ and remained improved at 24 months (ACD : $20 \pm 18, p<0.001$ vs. preoperative; CLD : $16 \pm 18, p<0.001$ vs. preoperative). No significant difference was noted in the changes at preoperation and 24-month follow-up between the groups ( $29 \pm 32$ vs. $47 \pm 31, p=0.08$ ) (Fig. 4A). Leg pain improved, with significant improvements noted at 7-day follow-up (ACD : $70 \pm 13$ vs. $19 \pm 18, p<0.001$; CLD : $63 \pm 26$ vs. $25 \pm 24, p<0.001$ ), and the improvement remained at 24 -month follow-up (ACD : 16 $\pm 20, p<0.001$ vs. preoperative; CLD : $12 \pm 18, p<0.001$ vs. preoperative). No significant difference was found in leg pain scores between the

Table 4. Mean percentage of preoperative disc height at each time point from 7-day to 24-month follow-up

\begin{tabular}{lccc}
\hline & ACD (\%) & CLD (\%) & $p$-value \\
\hline Postoperative & & & \\
7 days & $102.4 \pm 4.8$ & $92.0 \pm 7.6$ & $<0.001$ \\
1 month & $100.8 \pm 5.6$ & $93.9 \pm 8.3$ & $<0.001$ \\
3 months & $96.5 \pm 9.2$ & $86.9 \pm 8.4$ & $<0.001$ \\
6 months & $92.1 \pm 10.2$ & $83.7 \pm 9.2$ & 0.002 \\
12 months & $91.8 \pm 10.2$ & $84.2 \pm 9.0$ & 0.014 \\
24 months & $86.3 \pm 11$ & $79.2 \pm 10.0$ & 0.044 \\
\hline
\end{tabular}

Values are presented as mean \pm standard deviation. $A C D$ : annular closure device, CLD : conventional lumbar discectomy

Table 5. Comparison of clinical outcomes between preoperative and 24-month

\begin{tabular}{|c|c|c|c|c|}
\hline \multirow{2}{*}{ Outcome } & \multicolumn{2}{|c|}{$A C D$} & \multicolumn{2}{|c|}{ CLD } \\
\hline & Preop & Postop 24-month & Preop & Postop 24-month \\
\hline VAS back pain & $62 \pm 29$ & $20 \pm 18$ & $66 \pm 20$ & $16 \pm 18$ \\
\hline VAS leg pain & $70 \pm 31$ & $16 \pm 20$ & $63 \pm 26$ & $12 \pm 18$ \\
\hline SF-12P & $17 \pm 5$ & $26 \pm 5$ & $17 \pm 6$ & $27 \pm 4$ \\
\hline SF-12 M & $23 \pm 6$ & $30 \pm 5$ & $23 \pm 6$ & $31 \pm 5$ \\
\hline ODI & $47 \pm 15$ & $10 \pm 11$ & $52 \pm 24$ & $5 \pm 5$ \\
\hline
\end{tabular}

Values are presented as mean \pm standard deviation. ACD : annular closure device, CLD : conventional lumbar discectomy, Preop : preoperative, Postop : postoperative, VAS : visual analog scale, SF-12 P : 12-item short-form health survey scale physical, SF-12 M : 12-item short-form health survey scale mental, ODI : Oswestry Disability Index 

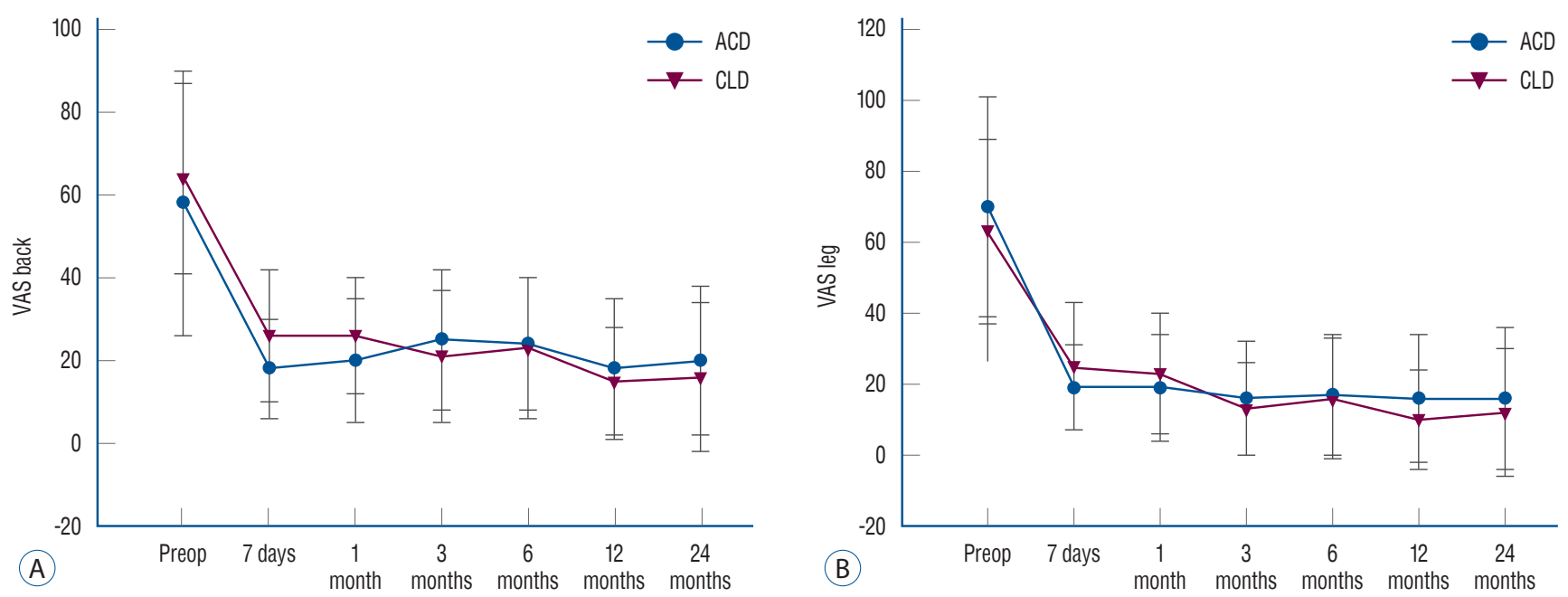

Fig. 4. VAS back (A) and leg (B) pain scores from preoperative to 24-month follow-up. ACD : annular closure device, CLD : conventional lumbar discectomy.

two groups at 24-month follow-up (ACD : 16 \pm 20 vs. CLD : 12 $\pm 18, p=0.55$ ) (Fig. 4B).

ODI scores were significantly improved at 24-month followup versus at preoperation in both the ACD (10 \pm 11 vs. $47 \pm 15$, $p<0.001)$ and CLD (5 \pm 5 vs. $52 \pm 24, p<0.001)$ groups. At 24 months, no significant difference was found in ODI scores between the ACD and CLD groups ( $10 \pm 11$ vs. $5 \pm 5, p=0.08)$ (Fig. 5).

SF-12 scores significantly improved at 24-month follow-up in both physical (ACD : $26 \pm 5, p<0.001$ vs. preoperative; CLD : $27 \pm 4, p<0.001$ vs. preoperative) and mental (ACD : $30 \pm 5$, $p<0.001$ vs. preoperative; CLD : $31 \pm 5, p<0.001$ vs. preoperative) scores in both the ACD and CLD groups. No significant difference was found in either physical ( $26 \pm 5$ vs. $27 \pm 4$, $p=0.37$ ) or mental ( $30 \pm 5$ vs. $31 \pm 5, p=0.40)$ scores (Fig. 6) between the two groups at 24-month follow-up.

\section{Disc re-herniation}

At 24-month follow-up, re-herniation was reported in one patient in the ACD group, and six cases in the CLD group $\left(\chi^{2}=4.04, p=0.044\right)$ (Fig. 7). No complications, such as device migration, subsidence, loosening, and fracture, were noted in any patient at 24 -month follow-up.

\section{DISCUSSION}

In the present study, we found that ACD is an effective

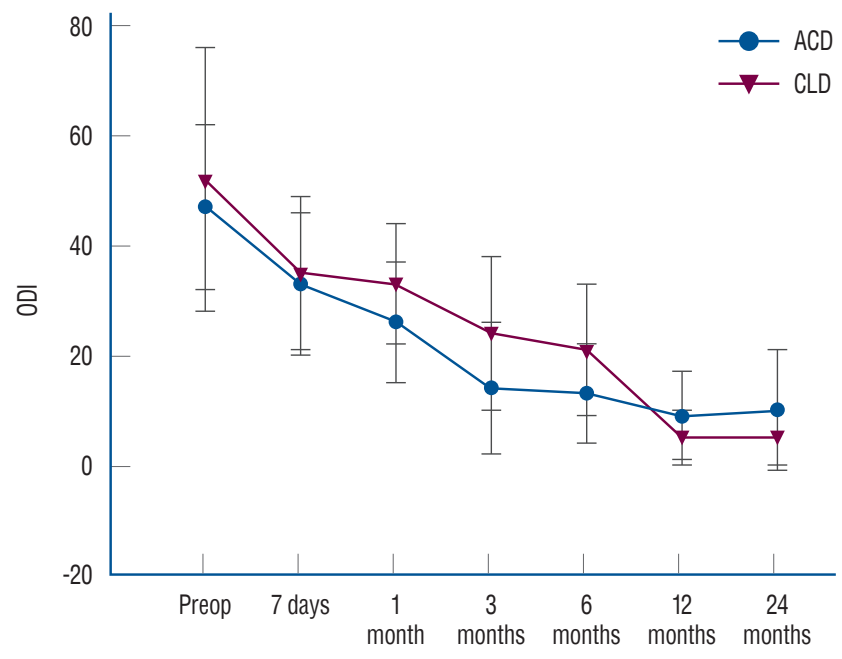

Fig. 5. Oswestry Disability Index (ODI) scores from preoperative to 24-month follow-up. ACD : annular closure device, CLD : conventional lumbar discectomy.

treatment for back and leg pain caused by single-level LDH, regardless of the LDH type.

Lumbar discectomy is a common procedure used to address LDH. Despite successful lumbar discectomy, symptoms persist in a substantial proportion of patients ${ }^{3,4}$. Re-herniation and re-operation rates above $12 \%$ have been reported ${ }^{7)}$, particularly in patients who undergo conservative discectomy, which leaves much of the nucleus intact. The subsequent risk of re-herniation in this group of patients is a concern and leaves many patients susceptible to re-operation ${ }^{11}$. Therefore, a novel ACD that allows preservation of much of the nucleus 

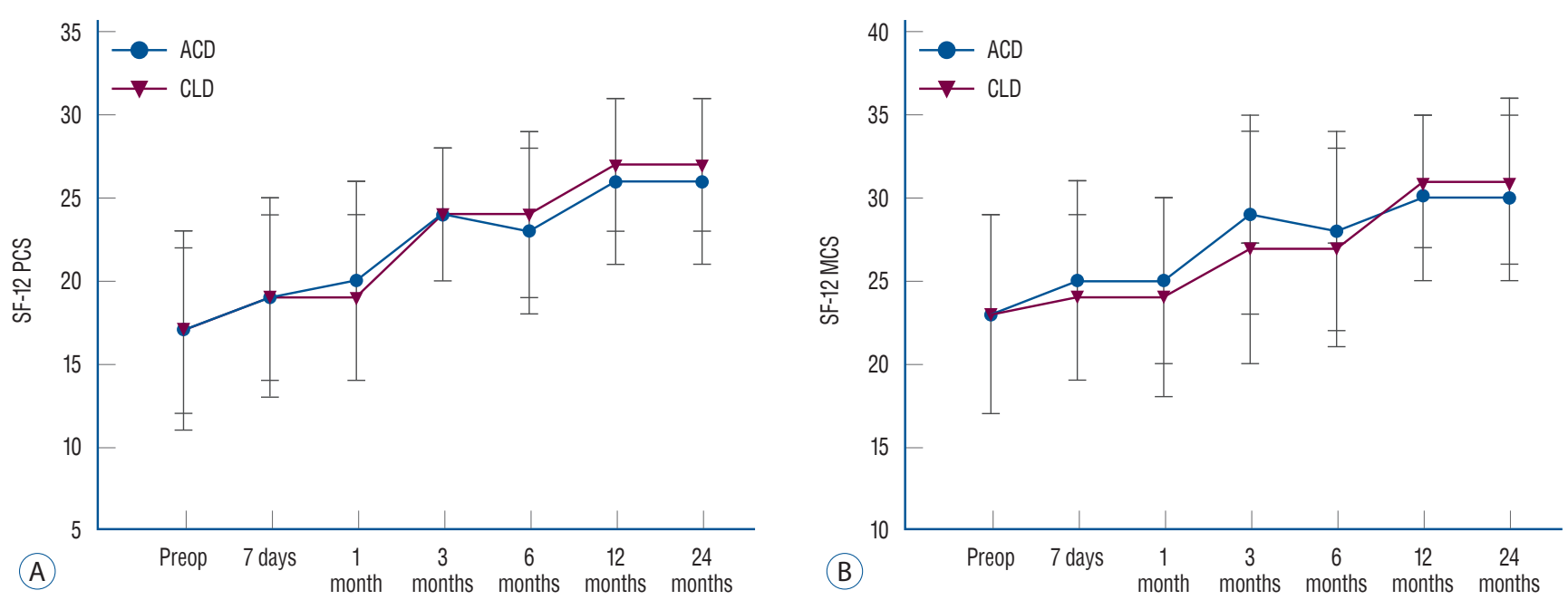

Fig. 6. Quality of life, physical (SF-12 PCS : A) and mental (SF-12 MCS : B) scores from preoperative to 24-month follow-up. ACD : annular closure device, CLD : conventional lumbar discectomy, SF-12 : 12-item short-form health survey scale, PCS : physical component summary, MCS : mental component summary.

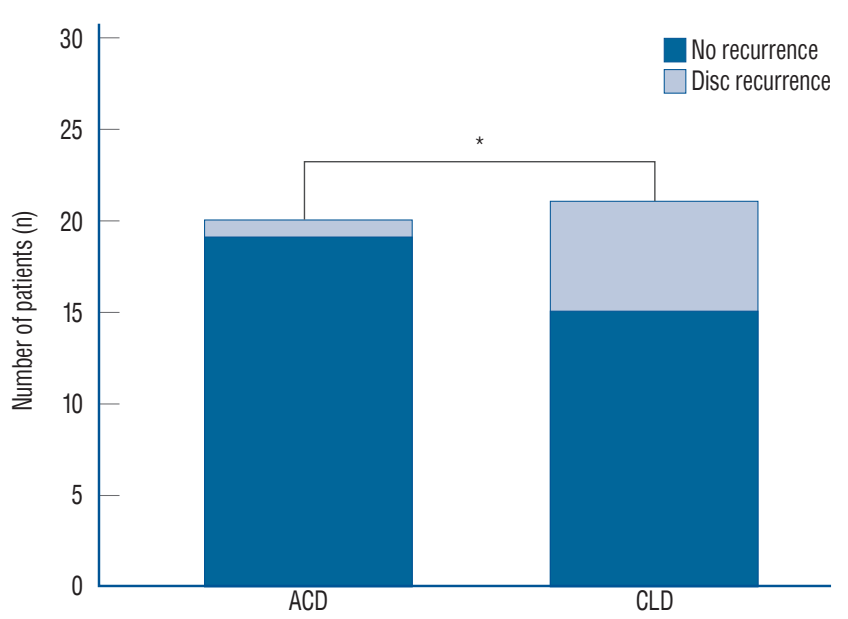

Fig. 7. Disc recurrence at 24 -months after surgery. ${ }^{*} p<0.005$. ACD : annular closure device, CLD : conventional lumbar discectomy.

while closing the annular defect has been developed. In this randomized controlled trial, we compared this device to traditional lumbar discectomy. We found that the device preserved lumbar disc height and was associated with significant improvements in pain severity and disability.

Our study found that the use of the ACD was successful in helping to maintain the integrity and stability of the annulus, which correlates well with studies examining similar techniques, ${ }^{1,91,14,17)}$. Patients treated with the closure device maintained disc height, when evaluated as both a raw measurement and a percentage of the initial disc height. Our observations that disc height was maintained at $92 \%$ and $86 \%$ of the initial values at 12 and 24 months, respectively, compares well with other studies that investigated the use of the same ACD described herein. Lequin et al. ${ }^{10)}$ noted a $92.8 \%$ maintenance of disc height at a 12-month postoperation and Ledic et al." found $91.5 \%$ and $90 \%$ disc heights at 12 - and 24 -month follow-ups, respectively. The preservation of disc height in our study was also associated with lower rates of re-herniation when compared with traditional discectomy. Our observation of 3.3\% re-herniation rate also corroborates previous studies of this closure device that have demonstrated re-herniation rates of up to $2.9 \% \%^{1,9,10,14)}$, a significant improvement on the rates reported for traditional discectomy, which can reach as high as $20 \%{ }^{18}$. Finally, our study demonstrated that the device limits the volume of disc material removed when compared with traditional discectomy. By decreasing the volume of resected disc material by $44 \%$, the ACD provides surgeons with the opportunity to perform a less aggressive discectomy. Our findings mirror those of Lequin et al. ${ }^{10)}$, who noted a $20 \%$ decrease in the amount of disc material removed with the closure device.

Our study reported a mean surgical time of 143 minutes in the ACD group, which was longer than that in the CLD group. This finding is in contrast to other studies of the device, which noted an average surgical time of 120 minutes, a duration not significantly different from the 126 minutes commonly reported for conventional discectomy ${ }^{10)}$. We hypothesize that this discrepancy could be attributed to inconsistencies in time 
measurement and recording among the studies, or potentially due to the learning curve associated with the use of the device. Future studies should utilize standardized procedural time measurement techniques and should be performed following the natural learning curve associated with the new technology. As surgeon familiarity with the device increases, the procedural time would naturally decrease.

Pain severity and disability scores improved in both the ACD and CLD groups, with both groups demonstrating immediate improvements that were maintained at 24-month follow-up. The improvements in the ACD group, which decreased from preoperative VAS scores of 62 (back) and 70 (leg) to 20 and 16, respectively, at 24 months compare favorably with previous studies that observed decreases in VAS to 1525/100 at 12 months and $10-20 / 100$ at 24 months $^{9,10)}$. Similarly, ODI scores improved from 47 at preoperation to 10 at 24-month follow-up, mirroring other studies that found ODI decreased to $15 / 100$ at both 12 and 24 months post-surgery ${ }^{9,10)}$.

This study has two important limitations. First, the 2-year follow-up, in which $70 \%$ or fewer patients were actually followed up, was short and limited the veracity with which conclusions can be applied in the long term. However, it provided important early information regarding the stability and survivability of the device. Our observations mirror those of other researchers who investigated this ACD and found that the device ensures maintenance of favorable clinical scores and lower rates of re-herniation. Second, the low sample size of our cohort limited the ability to extrapolate results to larger populations. Despite this limitation, the randomized nature of the study provided the highest level of evidence available, and the use of a control group comprised of patients undergoing conventional discectomy provided a valid and important comparison.

\section{CONCLUSIONS}

Our findings indicated that the Barricaid ${ }^{\circledR}$ (Intrinsic Therapeutics, Inc.) ACD is associated with excellent clinical scores following lumbar discectomy. A superior ability to maintain disc height and decrease re-herniation rates when compared with CLD in Korean patients was also demonstrated. When combined with the existing literature on ACD, these results provide a strong evidence to support its adoption to improve lumbar discectomy outcomes.

\section{CONFLICTS OF INTEREST}

No potential conflict of interest relevant to this article was reported.

\section{INFORMED CONSENT}

Informed consent was obtained from all individual participants included in this study.

\section{AUTHOR CONTRIBUTIONS}

\author{
Conceptualization : DAS, GYJ \\ Data curation : GYJ \\ Formal analysis : PGC \\ Funding acquisition : DAS, GYJ \\ Methodology : DAS, GYJ \\ Project administration : SHP \\ Visualization : SHP \\ Writing - original draft : PGC \\ Writing - review \& editing : PGC, DAS, SHP, GYJ
}

\section{- Acknowledgements}

This work was supported by the Industrial R\&D program of MOTIE/KEIT (10043086).

\section{References}

1. Bouma GJ, Barth $M$, Ledic D, Vilendecic M : The high-risk discectomy patient: prevention of reherniation in patients with large anular defects using an anular closure device. Eur Spine J 22 : 1030-1036, 2013

2. Brazier JE, Harper R, Jones NM, O'Cathain A, Thomas KJ, Usherwood T, et al. : Validating the SF-36 health survey questionnaire: new outcome measure for primary care. BMJ 305 : 160-164, 1992

3. Carragee EJ, Han MY, Suen PW, Kim D : Clinical outcomes after lumbar discectomy for sciatica: the effects of fragment type and anular competence. J Bone Joint Surg Am 85 : 102-108, 2003

4. Carragee EJ, Spinnickie AO, Alamin TF, Paragioudakis $S$ : A prospective 
controlled study of limited versus subtotal posterior discectomy: shortterm outcomes in patients with herniated lumbar intervertebral discs and large posterior anular defect. Spine (Phila Pa 1976) 31 : 653657, 2006

5. Davis RA : A long-term outcome analysis of 984 surgically treated herniated lumbar discs. J Neurosurg 80 : 415-421, 1994

6. Gray DT, Deyo RA, Kreuter W, Mirza SK, Heagerty PJ, Comstock BA, et al. : Population-based trends in volumes and rates of ambulatory lumbar spine surgery. Spine (Phila Pa 1976) 31 : 1957-1963, 2006

7. Heindel P, Tuchman A, Hsieh PC, Pham MH, D'Oro A, Patel NN, et al. : Reoperation rates after single-level lumbar discectomy. Spine (Phila Pa 1976) 42 : E496-E501, 2017

8. Kepley AL, Nishiyama KK, Zhou B, Wang J, Zhang C, McMahon DJ, et al. : Differences in bone quality and strength between Asian and Caucasian young men. Osteoporos Int 28 : 549-558, 2017

9. Ledic D, Vukas D, Grahovac G, Barth M, Bouma GJ, Vilendecic M : Effect of anular closure on disk height maintenance and reoperated recurrent herniation following lumbar diskectomy: two-year data. J Neurol Surg A Cent Eur Neurosurg $76: 211-218,2015$

10. Lequin $M B$, Barth $M$, Thome $C$, Bouma GJ : Primary limited lumbar discectomy with an annulus closure device: one-year clinical and radiographic results from a prospective, multi-center study. Korean J Spine $9: 340-347,2012$

11. Martin BI, Mirza SK, Flum DR, Wickizer TM, Heagerty PJ, Lenkoski AF, et al. : Repeat surgery after lumbar decompression for herniated disc: the quality implications of hospital and surgeon variation. Spine J 12 : 8997, 2012

12. McGirt MJ, Ambrossi GL, Datoo G, Sciubba DM, Witham TF, Wolinsky $J$, et al. : Recurrent disc herniation and long-term back pain after pri- mary lumbar discectomy: review of outcomes reported for limited versus aggressive disc removal. Neurosurgery 64 : 338-344, 2009

13. McGirt MJ, Eustacchio S, Varga P, Vilendecic M, Trummer M, Gorensek M, et al. : A prospective cohort study of close interval computed tomography and magnetic resonance imaging after primary lumbar discectomy: factors associated with recurrent disc herniation and disc height loss. Spine (Phila Pa 1976) 34 : 2044-2051, 2009

14. Parker SL, Grahovac G, Vukas D, Vilendecic M, Ledic D, McGirt MJ, et al. : Effect of an annular closure device (barricaid) on same-level recurrent disk herniation and disk height loss after primary lumbar discectomy: two-year results of a multicenter prospective cohort study. Clin Spine Surg $10:$ 454-460, 2016

15. Spengler DM : Lumbar discectomy. Results with limited disc excision and selective foraminotomy. Spine (Phila Pa 1976) 7 : 604-607, 1982

16. Strömqvist B, Fritzell $P$, Hägg 0 , Jönsson B; Swedish Society of Spinal Surgeons : The Swedish spine register: development, design and utility. Eur Spine J 18 Suppl 3 : 294-304, 2009

17. Trummer M, Eustacchio S, Barth M, Klassen PD, Stein S : Protecting facet joints post-lumbar discectomy: barricaid annular closure device reduces risk of facet degeneration. Clin Neurol Neurosurg 115 : 1440-1445, 2013

18. Watters WC 3rd, McGirt MJ : An evidence-based review of the literature on the consequences of conservative versus aggressive discectomy for the treatment of primary disc herniation with radiculopathy. Spine J 9 : 240-257, 2009

19. Yorimitsu E, Chiba K, Toyama Y, Hirabayashi K : Long-term outcomes of standard discectomy for lumbar disc herniation: a follow-up study of more than 10 years. Spine (Phila Pa 1976) 26 : 652-657, 2001 